\title{
Urinary tract infections in culled sows from Greek herds: prevalence and associations between findings of histopathology, bacteriology and urinalysis
}

Mihaela Cernat ${ }^{1 *} \mathbb{D}$, Vassilis Skampardonis ${ }^{1}$, Georgios A. Papadopoulos ${ }^{2}$, Fotios Kroustallas ${ }^{2}$, Sofia Chalvatzi ${ }^{2}$, Evanthia Petridou ${ }^{3}$, Vassilios Psychas ${ }^{4}$, Christina Marouda ${ }^{4}$, Paschalis Fortomaris ${ }^{2}$ and Leonidas Leontides ${ }^{1}$

\begin{abstract}
Background: Urinary tract infections (UTI) of sows characterized by cystitis, which may progress to ureteritis and pyelonephritis, can affect their productivity, longevity and welfare. In this study, we determined the prevalence of UTI by histopathology and bacteriology. Furthermore, we investigated possible associations between histologically confirmed cystitis and the results of urinalysis and urine cultures in culled sows from three farrow-to-finish herds in Greece.

Materials and methods: One hundred eighty-five routinely culled sows were included in the study. Their urinary bladder was collected from abattoirs and subjected to histopathology. Furthermore, urinalysis and urine cultures were performed on urine samples aseptically collected from the bladders.

Results: Histologically confirmed cystitis was evident in 85/185 (45.94\%) culled sows. Among those, 44 (51.76\%) suffered from acute and 41 (48.24\%) from chronic inflammation. The majority of positive urine cultures were due to colonization of the urinary tract with E.coli, which accounted for $55.81 \%$ of the total cases, followed by Staphylococcus spp. which accounted for $18.60 \%$ of detected infections. Evidence of cystitis was associated with bacteriuria and sows with bacteriuria were $2.30(P=0.03,95 \% \mathrm{Cl}: 1.10-4.83)$ times more likely to have histologically confirmed cystitis compared to sows with negative urine cultures. Bacteriuria was associated with proteinuria $(P<$ $0.01, \mathrm{OR}=9.72,2.63-35.88)$, increased urine $\mathrm{pH}(P<0.01,3.40,1.10-10.56)$ and presence of sediment $(P<0.01,6.00$, 1.50-23.76) in urine. Sows with proteinuria had $9.72(P<0.01,2.63-35.88)$ times higher odds of bacteriuria than those without. Histologically defined cystitis was associated with proteinuria $(P<0.01,2.03-13.20)$ and decreased urine $\mathrm{pH}(P<0.01,0.13-0.72)$. Sows with proteinuria were $5.18(P<0.01,2.03-13.2)$ times more likely to have histological lesions consistent with cystitis, than those without. For one unit increase in $\mathrm{pH}$, it was $3.20(P=0.006$, 1.39-7.69) times less likely for a sow to have chronic or acute cystitis compared to absence of cystitis.

(Continued on next page)
\end{abstract}

\footnotetext{
*Correspondence: tsernat@uth.gr

'Department of Epidemiology, Biostatistics and Economics of Animal

Production, School of Veterinary Medicine, University of Thessaly, 43132 Karditsa, Greece

Full list of author information is available at the end of the article
}

(C) The Author(s). 2021 Open Access This article is licensed under a Creative Commons Attribution 4.0 International License, which permits use, sharing, adaptation, distribution and reproduction in any medium or format, as long as you give appropriate credit to the original author(s) and the source, provide a link to the Creative Commons licence, and indicate if changes were made. The images or other third party material in this article are included in the article's Creative Commons licence, unless indicated otherwise in a credit line to the material. If material is not included in the article's Creative Commons licence and your intended use is not permitted by statutory regulation or exceeds the permitted use, you will need to obtain permission directly from the copyright holder. To view a copy of this licence, visit http://creativecommons.org/licenses/by/4.0/. The Creative Commons Public Domain Dedication waiver (http://creativecommons.org/publicdomain/zero/1.0/) applies to the data made available in this article, unless otherwise stated in a credit line to the data. 
(Continued from previous page)

Conclusion: In the studied population, UTI affected almost one out of two culled sows. Bacteriuria, which was more common among sows with UTI than those without, was mainly ascribed to members of the intestinal and environmental bacteria. Proteinuria and the existence of urine sediment which were associated with UTI, could be used as proxy traits for UTI in live sows.

Keywords: Sow, Cystitis, Bacteriuria, Urinalysis, Proteinuria, Turbidity

\section{Introduction}

Urinary tract infections (UTI) of sows, characterized by cystitis (inflammation of the urinary bladder) that may progress to ureteritis (inflammation of the ureters) and pyelonephritis (inflammation of the renal pelvis), are major health and welfare issues with economic impact to the swine industry because of sudden death, partly attributed to pyelonephritis and septicemia [1], or suboptimal reproductive performance [2-8]. UTI are associated with colonization of the normally sterile urinary tract with bacteria, which are most usually members of the fecal microbiota, ascending from the vagina and distal urethra [9], mainly prepartum [10]. In sows with UTI, ureteric valves are shortened from normal length. In case of cystitis, bacteria can reflux back to the kidney [11]. Bacteriuria (culture positive urine), however, may not be always detected in samples from sows with UTI or may be detected from sows without UTI $[7,12]$.

The prevalence of UTI which was estimated in live sows [13-16] as well as at abattoirs [3, 12, 17], by either reagent strip tests, urine culture or histopathology, vary considerably from 15.8 [15] to 58\% [16]. There are many reasonable explanations for this wide variation in estimates which challenge the comparability among study results; the most important being the different case definitions, and the different parity structure of the studied sow populations. The reagent strip tests which have been applied in some of the on-farm studies are ineffective, especially in the diagnosis of chronic UTI [12], thus underestimating UTI prevalence. Madec and Leon (1992) detected UTI in $23.5 \%$ of sows of parity $\geq 5$ whereas none of first-parity sows had evidence of UTI. Earlier studies [18-21], investigating the causes of sow mortality, reported the frequency of UTI, after defining diagnosis either based on gross pathology or on bacterial isolation, ranging from approximately $6[20,21]$ to $19.4 \%$ [18]. Nonetheless, UTI remain largely under-diagnosed and therefore untreated [7, 22], despite being associated with several periparturient clinical problems which may lead to producers' decision for early culling [3-6] of sows. The most common bacteria associated with cases of UTI were E. coli, Streptococci, Staphylococci, and Actinobaculum suis, either alone or in combination [23]. In diagnosed cases of UTI, clinical management included treatment with broad spectrum antibiotics [11].
Diagnosis of UTI in live sows is based on urinalysis and urine culture results. Histopathology, being the "gold standard" for diagnosis, is the method of choice in dead animals. Compared to the "gold standard", urinalysis and bacteriology demonstrated low sensitivity but relatively high specificity in detecting UTI [12]. Because of increased possibilities of bacterial contamination during sampling in live animals, the positive predictive value of bacteriological culture was reported as being relatively low [3].

To the best of the authors' knowledge, the prevalence of UTI has not been reported in multiparous sows of Greek herds. Similarly, the bacteria most frequently involved and their antibiotic sensitivity profile were not determined before. The latter is important, considering anecdotal reports highlighting the significance of UTI for sow's longevity and productivity, especially during the warmest period of the year from early May to late September. Thus, the objective of the present study was threefold: i) to estimate the prevalence of histopathologically confirmed cystitis in culled sows from three Greek farrow-to-finish herds, ii) to perform urinalysis and urine culture on samples from culled sows of the herds, isolate the bacteria involved in bacteriuria incidents and determine their sensitivity profile, and iii) to investigate possible associations between cystitis and the results of urinalysis and urine culture.

\section{Materials and methods Study population}

Three indoor, farrow-to-finish herds were involved in our study that lasted from January 2019 until April 2020. The owners gave their written consent for participation in the study. All herds complied with EU directive 2001/88/DC on animal welfare. The herds comprised 250 (Herd A), 350 (Herd B) and 370 sows (Herd C), with PIC, Danbred and Topigs Norvsin genetic lines, respectively. Culling of sows was decided by the manager/owner of each herd without any intervention of investigators who were only informed about scheduled culling in order to organize sample collection from abattoirs.

\section{Animals and abattoir sampling protocol}

Council Directive 93/119/EC on the protection of animals during slaughter was standard practice for all sows included in the study. 
Almost $50 \%$ of sows routinely culled in the designated herds during the study period were included. Sample collection was performed at the abattoirs with minimum interference in the normal slaughtering process. Sow carcasses did not pass through scalding water; they were skinned immediately after stunning and exsanguination. Urinary bladders were removed before evisceration to minimize possible contamination from gut content. Immediately after removal, the neck of the bladder was fastened [12]. Subsequently, the surface of the bladder was surgically scrubbed and mid-flow urine was collected after gently shaking the bladder. Urine samples from each sow were collected in two sterile containers, one destined for urinalysis and the other for culture, from a small incision (approximately $1 \mathrm{~cm}$ ) made in the fundus of the bladder with surgical blade. Urine samples and bladders were cooled immediately using portable thermo-insulated containers with ice packs and transferred to the laboratory for analysis. Macroscopic and microscopic evaluation was performed on all urine samples that arrived at the laboratory in acceptable condition within 6 to $12 \mathrm{~h}$ after collection.

\section{Macroscopic examination of bladders}

Urinary bladders were macroscopically examined, after dissection with scissors along their sagittal axis, from the neck to apex to expose the mucosa. Lesions recorded during gross examination of urothelium were: 1 ) superficial mucosal hyperemia and hemorrhages, 2) diffusely thickened, hyperplastic bladder wall and 3) lesions regarding the integrity of the urothelium, such as ulcerations, mucosal edema and fibrinopurulent exudate. Presence of concretions or calculi was recorded and subsequently examined microscopically. Thereafter, the bladders were thoroughly cleaned, and lesions were closely re-observed. Finally, they were categorized as either non-affected when they had no lesions or calculi, or as affected when lesions or concretions were observed (Fig. 1).

\section{Histopathological examination of bladders}

Full thickness representative samples from the neck and the fundus of all urinary bladders were obtained and fixed in 10\% neutral-buffered formalin for minimum 48 h. Samples were further processed routinely, embedded in paraffin and sectioned at $4 \mu \mathrm{m}$ thickness. Sections were stained with hematoxylin and eosin $(H \& E)$ and were assessed blindly by two pathologists. Distribution of lesions was defined as focal, multifocal or diffuse [12]. Cystitis was diagnosed when at least one focal area of inflammatory infiltration was observed. Urinary bladders without inflammatory infiltration were considered histologically normal (Fig. 2). Bladders with slaughter-related hyperemia were categorized as non-affected when hyperemia was not accompanied with additional lesions [24] (Fig. 3).

Distinction between acute and chronic cystitis was determined by the type of cell infiltration (neutrophils and macrophages in acute and lymphocytes or plasma cells in chronic), the state of urothelium (necrosis and desquamation of the epithelium indicated an acute inflammation) and the degree of fibrosis in chronic conditions [25]. Cystitis was categorized as either acute when areas with necrosis and exfoliation of urothelial cells were observed along with mild or moderate superficial hyperemia and marked leukocytic mucosal infiltration, or chronic, when lymphoplasmacytic infiltration beneath the epithelium and areas with mild submucosal fibrosis were observed (Fig. 4).

\section{a) Non-affected urinary urinary}

bladder b) Gross view of affected urinary bladder containing sabulous material. The mucosa is hyperemic along with subserosal hemorrhages

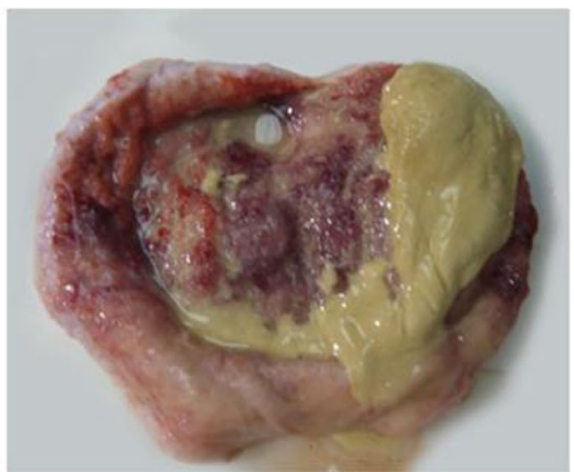

Fig. 1 Macroscopic view of non-affected (a) and affected (b) urinary bladders, a) Non-affected urinary urinary bladder. b) Gross view of affected urinary bladder containing sabulous material. The mucosa is hyperemic along with subserosal hemorrhages 


\section{a) Non-affected urinary bladder layers (X4, H\&E) b) Affected urinary bladder with lymphoplasmacytic infiltration beneath the urothelium. (X100, H\&E)}

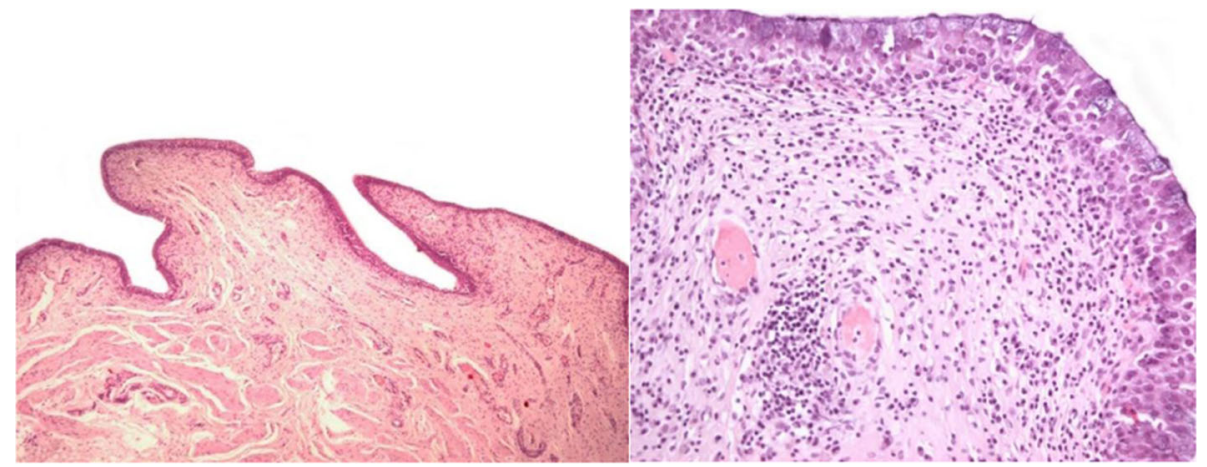

Fig. 2 Microscopic view of non-affected (a) and affected (b) urinary bladder (H\&E stain). a) Non-affected urinary bladder layers (X4, H\&E) b) Affected urinary bladder with lymphoplasmacytic infiltration beneath the urothelium. (X100, H\&E)

Inflammation severity was categorized according to distribution, intensity/degree of leukocytic lamina propria inflammation and infiltrated layers of bladder wall. In particular, inflammation was classified as: i) mild when focal inflammatory infiltration was observed, but did not extend to deeper layers of the wall bladder, ii) moderate when bladders had multifocal or diffuse distribution of inflammatory infiltration and prominent leukocytic infiltration of the lamina propria, and iii) severe when diffuse distribution of inflammation, marked infiltration of mononuclear cells, and exfoliation of the epithelium, with or without mucosal hemorrhages, was noticed $[12,24,25]$.

\section{Urinalysis}

For consistency and comparability of results among samples, especially for the examination of urine sediment's characteristics and constituents, we collected $10 \mathrm{ml}$ of urine from all sampled bladders [26, 27]. Initially, the

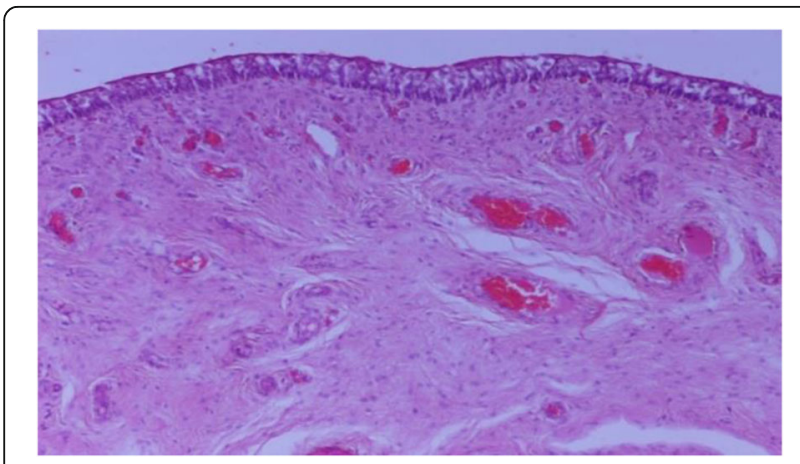

Fig. 3 Urinary bladder with dilated and congested capillaries. Absence of inflammation. H\&E stain $\times 100$ ) urine samples were transferred into conical tip tubes and were evaluated for turbidity. Urine $\mathrm{pH}$ was measured by an electric $\mathrm{pH}$ meter (HD2105.1 ${ }^{\circ}$ delta OHM), and protein estimation was done with the nitric acid method [28]. Then, samples were centrifuged at 1500 rpm for $5 \mathrm{~min}$ and subsequently, the presence or absence of sediment was recorded. The infranatant product of centrifugation was observed under light microscope $(x$ 40 and $\times 100$ ). Cellular components (red blood cells and leukocytes) were recorded [12]. Crystals were identified and characterized based on their shape, size and consistency, using high power magnification $(\times 200$ and $\times 400)$ and infrared spectroscopy $[29,30]$.

\section{Urine culture}

Samples for culture were transferred into $1 \mathrm{ml}$ conical tip tubes using a disposable pipette, after gently inverting the original container in order to mix the content. Subsequently, using a sterile loop or a capillary pipette, samples were inoculated onto Columbia agar containing 5\% sheep blood, and onto MacConkey agar plates, and incubated at $37^{\circ} \mathrm{C}$ for $24 \mathrm{~h}$. Two separate samples were inoculated and incubated respectively in $\mathrm{CO}_{2}$ enriched atmosphere, for $24-48 \mathrm{~h}$ at $37^{\circ} \mathrm{C}$, and anaerobically for 48-96 h. The bacterial count per $\mathrm{ml}$ was assayed after spreading a standard quantity of urine onto $5 \%$ sheep blood agar, incubated aerobically for $24 \mathrm{~h}$ at $37^{\circ} \mathrm{C}$ [31] Pure or mixed cultures with more than $10^{5} \mathrm{CFU} / \mathrm{ml} \mathrm{bac-}$ teria were considered positive [12]. Bacteria identification was performed using biochemical testing; their sensitivity to commonly prescribed antibiotics, namely ampicillin, amoxicillin + clavulanic acid, enrofloxacin, tetracycline, cephalexin, colistin, ceftazidime and erythromycin, was tested. Choice of antibiotics was based on routinely employed methodology of certified 


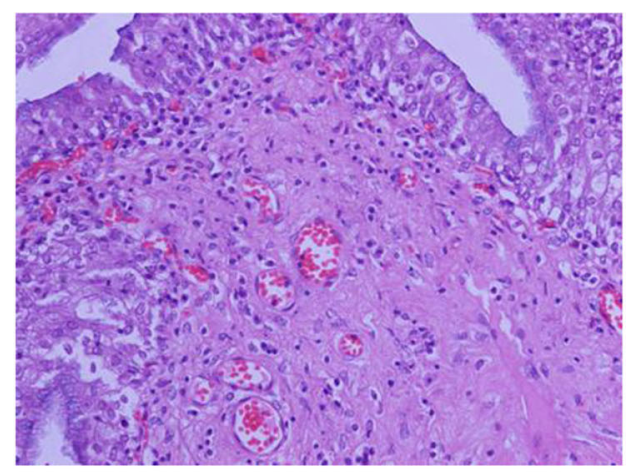

a) Chronic inflammatory cell infiltration

composed mainly of lymphocytes and

plasmocytes in the lamina propria. The

urothelium remains intact (X200, H\&E)

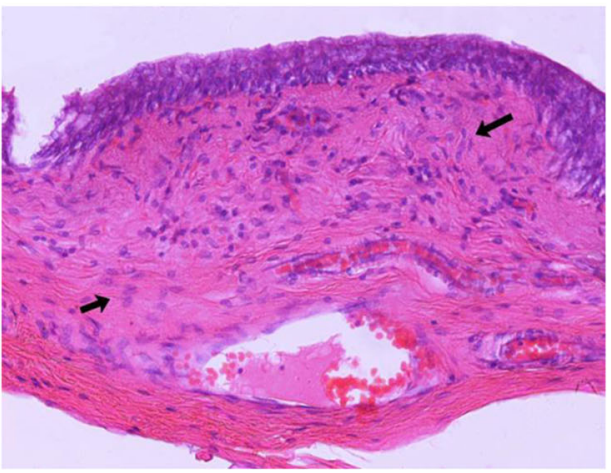

b) Different region of the same case as (a)

where mild fibrosis is observed. The arrows

point to the active fibroblasts (x200, H\&E)

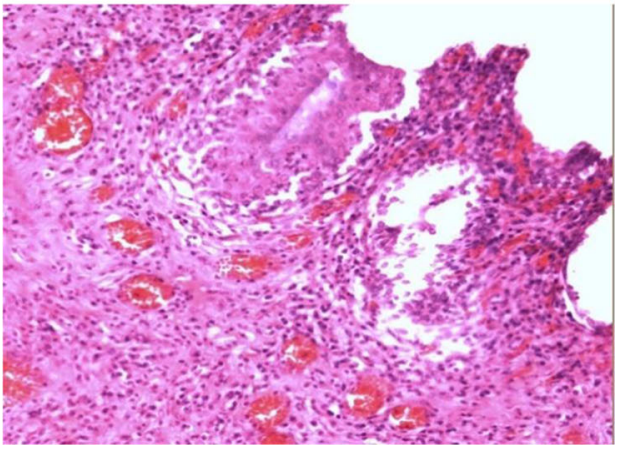

c) Acute cystitis. Marked desquamation of

the epithelium, hemorrhagic areas and

diffuse leukocytic infiltration (mainly

lymphocytes and few macrophages in the

ulcerative areas). (x100, H\&E)

Fig. 4 Chronic (a,b) versus acute (c) cystitis (hematoxylin and eosin stain). a Chronic inflammatory cell infiltration composed mainly of lymphocytes and plasmocytes in the lamina propria. The urothelium remains intact (X200, H\&E). b Different region of the same case as (a) where mild fibrosis is observed. The arrows point to the active fibroblasts ( $\times 200$, H\&E). c Acute cystitis. Marked desquamation of the epithelium, hemorrhagic areas and diffuse leukocytic infiltration (mainly lymphocytes and few macrophages in the ulcerative areas). ( $\times 100, H \& E$ )

laboratories providing services to veterinary practitioners. Those antibiotics are commonly prescribed in practice in Greece.

\section{Statistical analysis}

All statistical analyses were performed using Stata 13.1 (Stata Statistical Software, College Station, Texas). Descriptive statistics of collected data were calculated. Kruskal-Wallis ANOVA was used to compare parity distributions among herds. Pearson's $\chi^{2}$ tests were used to compare the proportion of sows with histologically confirmed cystitis and bacteriuria, among the three herds, across parities and among season of culling. One-way ANOVA was used to compare the average urine $\mathrm{pH}$ values across herds, parities and season of culling. A linear regression model was employed to investigate the possible association between the $\mathrm{pH}$ and the presence of crystals in urine. Pearson's $\chi^{2}$ tests were additionally used to test for possible associations between urinalysis parameters and to compare the frequencies of antibiotic sensitivity of each isolated bacteria species among herds.

\section{Associations between histologically confirmed cystitis and urinalysis parameters}

We employed an ordered logistic regression model to test any possible association between cystitis, classified as absent, acute or chronic, and urinalysis parameters. Cystitis, was the dependent variable, while urine 
turbidity, $\mathrm{pH}$, presence of sediment, crystals, red blood cells, leukocytes and protein were used as independent covariates. For model building we followed the procedure described by Lo Fo Wang et al. (2004) [32]. All independent variables were initially screened one by one. During this process, a significance level of 0.25 was used [33]. Then variables with $P<0.25$ were subjected simultaneously to a full model, subsequently reduced by backwards elimination [34] until only significant $(P<0.05)$ variables remained. Two-factor interactions were created between the remaining variables and subjected one at a time to the model. Finally, we tested previously deleted variables one-by-one to the final model, to ensure that no variable with significant impact to the model was omitted. The proportional odds assumption of ordered logistic regression models was tested using the oparallel post-estimation command [35]. Goodness of fit of the final model was tested with the ologitgof post-estimation command [36].

\section{Association between macroscopical lesions in urinary bladders and histologically confirmed cystitis}

The evaluation of the association between macroscopical lesions on the urothelium of the bladders and histological lesions consistent with cystitis was evaluated in a logistic regression model. The presence or absence of histologically confirmed cystitis was the dependent variable while the presence or absence of gross lesions in the urinary bladder was the independent variable.

\section{Associations between bacteriuria and urinalysis parameters}

For the investigation of possible associations between bacteriuria and the parameters examined in urinalysis we employed logistic regression modelling. Model building followed the procedure previously described.

\section{Association between bacteriuria and histologically confirmed cystitis}

The significance of the association between bacteriuria and the presence of cystitis was tested in a logistic model. In addition, an ordinal logistic regression model was employed to investigate any association of bacteriuria with inflammatory status of the bladder (absent, acute or chronic cystitis). Model building followed the procedure described above.

\section{Results}

A total of 185 culled sows were sampled. Fifty-seven (57) originated from herd A, sixty-four (64) from herd B and sixty-four (64) from herd C. Their parities ranged from 1 to 9 , with a median of 6 . Specifically, the median parity was 5 (range 1-7), 6 (range 1-9) and 6 (range 1-
8) in sows from herd A, B and C, respectively; parity distributions did not differ $(P=0.33)$ among herds.

Gross examination of urinary bladders revealed that $136 / 185(73.50 \%)$ had no remarkable lesions, while in the remaining, congestion was observed in 39/185 (21.08\%), hemorrhages were noted in $4 / 185(2.16 \%)$, concretions were present in $4 / 185(2.16 \%)$, while $2 / 185$ (1.08\%) urinary bladders had simultaneously hemorrhages, congestion and concretions. Histologically, cystitis was evident in 85/185 (45.94\%) sows. Among those, $44(51.76 \%)$ suffered from acute and 41 (48.24\%) from chronic inflammation. Among sows with chronic cystitis, the inflammation was mild $(39 / 41,95.12 \%)$ or moderate (2/41, 4.88\%), while among cases of acute cystitis, 27/44 (61.36\%) were classified as mild, $13 / 44$ (29.55\%) as moderate and $4 / 44(9.09 \%)$ as severe. There were no significant differences in the prevalence of cystitis in sows among herds $(P=0.59)$, across different parities $(P=$ $0.90)$ and among seasons of the year $(P=0.09)$.

Urinalysis data were available from 134 of the 185 sampled sows, because of the absence or inadequate quantity of urine in the bladders of the remaining 51 sows (Table 1). Turbid urine was found in $35 / 134$ $(26.12 \%)$ sows. Sediment was recorded in 53/134 (39.55\%) sows. Leukocytes and red blood cells were identified in 20/134 (14.93\%) and 19/134 (14.18\%) sows, respectively; the urine of $11 / 134$ (8.21\%) sows had leukocytes and red blood cells. Crystals were detected in 46/ 134 (34.33\%) sows. The main component of all but one of the urinary crystals identified, was calcium oxalate and the remaining was struvite.

The average urine $\mathrm{pH}$ did not differ either among herds $(P=0.37)$, or across parities $(P=0.86)$ or among season of culling $(P=0.42)$. The presence of crystals was associated with urine $\mathrm{pH}(P<0.001)$; sows with crystals in their bladder had higher $\mathrm{pH}$ values by on average 0.32 $(P<0.001,0.16-0.49)$ units. Urine turbidity was associated with presence of sediment $(P<0.001)$. Specifically, sows with turbid urine had 8.60 (95\% CI: 3.60-20.49) times higher odds of having urine sediment compared to sows with clear urine.

Urine-culture data were available from 171 sows. Overall, the frequency of positive urine cultures was 38/ $171(22.22 \%)$ and it did not differ either among herds $(P=0.44)$, or across parities $(P=0.82)$ or among seasons of culling $(P=0.12)$. Cystitis was histologically confirmed in $23 / 38(60.53 \%)$ of sows with bacteriuria.

The frequency of isolated bacteria species is presented in Table 2. Among positive urine samples there were $5 /$ 38 (13.16\%) with mixed infections, whereas the remaining 33/38 (86.84\%) were pure cultures. The sensitivity profile of isolated bacteria is shown in Table 3 . The sensitivity patterns of the isolated bacteria did not differ among herds (the lowest $P=0.13$ ). 
Table 1 Results of urinalysis on samples collected from the urinary bladders of 134 culled sows from three farrow-to-finish Greek herds

\begin{tabular}{|c|c|c|c|c|}
\hline Laboratory findings & In total $(n=134)$ & Herd A $(n=27)$ & Herd B $(n=54)$ & Herd C $(n=53)$ \\
\hline \multicolumn{5}{|l|}{ Urine appearance } \\
\hline Clear & 99 (73.88\%) & $18(66.67 \%)$ & $41(75.93 \%)$ & $40(75.47 \%)$ \\
\hline Turbid & 35 (26.12\%) & 9 (33.33\%) & $13(24.07 \%)$ & $13(24.53 \%)$ \\
\hline \multicolumn{5}{|l|}{ Proteinuria } \\
\hline No & $104(77.61 \%)$ & $20(74.07 \%)$ & $43(79.63 \%)$ & $41(77.36 \%)$ \\
\hline Yes & 30 (22.39\%) & 7 (25.93\%) & $11(20.37 \%)$ & $12(22.64 \%)$ \\
\hline \multicolumn{5}{|l|}{ Sediment } \\
\hline Absence & 81 (60.45\%) & $13(48.15 \%)$ & $32(59.26 \%)$ & $36(67.92 \%)$ \\
\hline Presence & 53 (39.55\%) & $14(51.85 \%)$ & $22(40.74 \%)$ & 17 (32.08\%) \\
\hline \multicolumn{5}{|l|}{ Leucocytes } \\
\hline Absence & $114(85.07 \%)$ & $24(88.89 \%)$ & 46 (85.19\%) & $44(83.02 \%)$ \\
\hline Presence & 20 (14.93\%) & $3(11.11 \%)$ & $8(14.81 \%)$ & 9 (16.98\%) \\
\hline \multicolumn{5}{|l|}{ Red blood cells } \\
\hline Absence & $114(85.07 \%)$ & $24(88.89 \%)$ & $43(79.63 \%)$ & $47(88.68 \%)$ \\
\hline Presence & 20 (14.93\%) & $3(11.11 \%)$ & $11(20.37 \%)$ & $6(11.32 \%)$ \\
\hline \multicolumn{5}{|l|}{ Crystals } \\
\hline Absence & 88 (65.67\%) & $16(59.26 \%)$ & $35(64.81 \%)$ & 37 (69.81\%) \\
\hline Presence & 46 (34.33\%) & $11(40.74 \%)$ & 19 (35.19\%) & 16 (30.19\%) \\
\hline Average $\mathrm{pH}( \pm \mathrm{SD})$ & $7.27( \pm 0.043)$ & $7.33( \pm 0.111)$ & $7.23( \pm 0.620)$ & $7.30( \pm 0.071)$ \\
\hline
\end{tabular}

\section{Association between histologically confirmed cystitis and} urinalysis parameters

After the screening process, five parameters, namely, urine turbidity, proteinuria, $\mathrm{pH}$, presence of sediment and presence of leukocytes were selected for the full model. After model building, proteinuria and $\mathrm{pH}$ were significant. Their interaction was not statistically significant $(P=0.63)$. The assumption of proportionality of odds was not violated $(P=0.15$, Brant test). HosmerLemeshow (HL) $(P=0.28)$ and Pulkstenis-Robinson (PR) $(P=1.00)$ tests suggested an overall adequate fit of the model to the data. The odds of acute and chronic cystitis combined, versus absence of cystitis were 5.18 ( $P=$ 0.001, 95\% CI: 2.03-13.20) times greater in the presence of proteinuria. Likewise, for one unit increase in $\mathrm{pH}$, it was $3.20(P=0.006,1.39-7.69)$ times less likely for a sow to have chronic or acute cystitis compared to absence of cystitis.

\section{Association between macroscopic lesions in urinary bladders and histologically confirmed cystitis}

Urinary bladders with macroscopic lesions were 5.60 $(P<0.001,2.70-11.80)$ times more likely to have histological lesions of cystitis, either acute or chronic, compared to those without gross lesions.

\section{Association between bacteriuria and urinalysis parameters}

In the screening process, all urinalysis parameters were eligible for inclusion in the full model. After model building, proteinuria, presence of sediment and $\mathrm{pH}$ were retained. The 2-way interactions examined were not

Table 2 Frequency of isolated bacteria species in 38 culled sows with positive urine cultures. Mixed infections were observed in 5 sows

\begin{tabular}{lllll}
\hline & In total & Herd A & Herd B & Herd C \\
\hline Escherichia coli & $24 / 43(55.81 \%)$ & $7 / 12(58.33 \%)$ & $12 / 19(63.16 \%)$ & $5 / 12(41.67 \%)$ \\
Enterococcus spp. & $4 / 43(9.30 \%)$ & $2 / 12(16.67 \%)$ & $1 / 19(5.26 \%)$ & $1 / 12(8.33 \%)$ \\
Enterobacter spp. & $4 / 43(9.30 \%)$ & $1 / 12(8.33 \%)$ & $2 / 19(10.53 \%)$ & $1 / 12(8.33 \%)$ \\
Staphylococcus spp. & $8 / 43(18.60 \%)$ & $2 / 12(16.67 \%)$ & $2 / 19(10.53 \%)$ & $4 / 12(33.34 \%)$ \\
Klebsiella spp. & $1 / 43(2.33 \%)$ & $0 / 12(0.00 \%)$ & $1 / 19(5.26 \%)$ & $0 / 12(0.00 \%)$ \\
Actinobaculum suis & $2 / 43(4.66 \%)$ & $0 / 12(0.00 \%)$ & $1 / 19(5.26)$ & $1 / 12(8.33 \%)$ \\
\hline
\end{tabular}


Table 3 Sensitivity of isolated bacteria to ampicillin (AMP), amoxicillin + clavulanic acid (AMC), enrofloxacin (ENR), tetracycline (TET), cephalexin (CN), colistin (COL), ceftazidime (CAZ) and erythromycin (ERY)

\begin{tabular}{|c|c|c|c|c|c|c|c|c|c|}
\hline \multirow[b]{2}{*}{ Isolated bacteria } & \multirow[b]{2}{*}{ Total cases isolated } & \multicolumn{8}{|c|}{$\%$ percentage of sensitivity } \\
\hline & & AMP & AMC & ENR & TET & $\mathrm{CN}$ & COL & CAZ & ERY \\
\hline Escherichia coli & 24 & 25 & 66.66 & 95.83 & 41.62 & 79.16 & 75 & 91.66 & 66.66 \\
\hline Enterococcus spp. & 4 & 0 & 75 & 100 & 25 & 75 & 100 & 100 & 100 \\
\hline Enterobacter spp. & 4 & 50 & 75 & 100 & 75 & 75 & 100 & 100 & 100 \\
\hline Staphylococcus spp. & 8 & 25 & 62.5 & 87.5 & 25 & 87.5 & 100 & 87.5 & 62.5 \\
\hline Klebsiella spp. & 1 & 0 & 0 & 0 & 0 & 100 & 100 & 100 & 0 \\
\hline Actinobaculum suis & 2 & 0 & 100 & 100 & 50 & 100 & 100 & 100 & 100 \\
\hline
\end{tabular}

statistically significant. HL $(P=0.79)$ test suggested an overall adequate fit of the model to the data. Sows with proteinuria had $9.72(P<0.01 ; 2.63-35.88)$ times higher odds of bacteriuria than those without. Sows with sediment in their bladder had $6.00(P=0.01 ; 1.50-23.76)$ times higher odds of bacteriuria, compared to sows without sediment. Lastly, for one unit increase of urine $\mathrm{pH}$ it was $3.40(P=0.01 ; 1.10-10.56)$ times more likely for a sow to have bacteriuria.

\section{Association between bacteriuria and histologically confirmed cystitis}

Sows with bacteriuria were $2.30(P=0.03 ; 1.10-4.83)$ times more likely to have histological lesions consistent with cystitis in their urinary bladders, than sows with negative urine cultures. Moreover, an association of bacteriuria with the inflammatory status of the bladder was detected; acute cystitis was $3.55(P=0.004 ; 1.48-8.50)$ times more likely to be accompanied by bacteriuria when compared to absence of cystitis. In contrast, the odds of bacteriuria did not differ $(P=0.39)$ either between sows with chronic or no cystitis or between sows with acute or chronic cystitis $(P=0.09)$.

\section{Discussion}

The effect of diseases of the urogenital track, such as endometritis and cystitis, is considered an important determinant of farms' economic output and animals' welfare status [37]. Biksi et al. (2002) reported positive association between cystitis and endometritis, while Gmeiner et al. (2007) [38] suggested the existence of a bidirectional reservoir of infections, with non-specific and opportunistic pathogens, between the uterus and the urinary tract. In our study, we estimated the prevalence of UTI in culled sows from 3 swine herds in Greece through histopathological evaluation of the urinary bladder, urine culture and urinalysis. Furthermore, we investigated possible associations between histopathologically defined cystitis $[3,12]$ and the results of urinalysis and urine cultures.
The estimated prevalence of cystitis was within the range of previously studies in culled sows [3, 12, 17]. Similarly to findings of Bellino et al. (2013) and Grattarola et al. (2010), we found that bacteriuria was less frequent than histologically confirmed cystitis by almost $50 \%$. In line with previous studies $[16,39]$ we detected E.coli as the leading cause of bacteriuria, accounting for approximately $50 \%$ of all cases, followed by Staphylococcus spp; these bacteria were cumulatively responsible for over $70 \%$ of cases of bacteriuria. Most likely, these cases were the result of ascending infections which are considered common because of the female's short urethra and the physiological relaxation of the sphincter muscle peripartum. These bacteria which likely originate from sows' intestinal tract, contaminate the environment of pig houses and ascend and colonize the lower part of the urinary tract [12, 40, 41]. Interestingly, we found only 2 sows infected with Actinobaculum suis, a specific contaminant of the urinary tract with descending significance compared to data reported in the past mainly due the wide application of artificial insemination [12, 42].

E. coli and other Gram-negative (Enterobacter spp.) and -positive (Staphylococcus spp., Enterococcus spp.) isolates were not sensitive to most of the antibiotics tested. Although the range of antibiotics included in our sensitivity evaluation panel may be considered narrower than those of previous reports $[16,43]$, our results may indicate that there is a significant reduction of efficacy of commonly prescribed antibiotics in incidents of UTI in sows in Greek herds.

The results showed that almost 1 out of 3 tested sows had turbid urine. Among sows with bacteriuria, urine turbidity was recorded in almost 2 out of 3 sows. Urine turbidity was associated with presence of sediment, which in turn, was associated with crystalluria. Urine may sometimes contain less sediment compared to the amount observed in the bladder through ultrasonographic depiction [44]. However, our collection method of mid-stream urine after gentle shaking of urinary bladders for about a minute led to a rather homogenous distribution of urine sediment. We microscopically examined the detected 
sediment, and recorded all of its constituents; i.e., red blood cells, leukocytes and crystals. Crystals in urine may be either the result of abnormalities in the mineral composition of the feed, such as imbalance in calcium and phosphorus intake [45], and/or the result of insufficient water consumption and/or, alternatively, be induced by local infections [46].

The notion is that higher parity predisposes both to endometritis and to cystitis [6, 47-49]. In our study, parity was not associated either with histologically confirmed cystitis or with bacteriuria, similarly to reports from Biksi et al. (2002) [50] and Piassa et al. (2015) [16]. The debate among studies on the existence of an association between UTI and parity distribution of sows may be a reflection of differences in parity distribution of studied sow populations. We did not find any significant variation in cystitis or bacteriuria frequency among herds or among-season. Sows with proteinuria were more likely to have histological lesions consistent with acute or chronic cystitis than those without proteinuria; they were more likely to have positive urine cultures than those without proteinuria. Proteinuria, the presence of abnormal protein level in urine, is a consequence of either abnormal transglomerular passage of proteins, because of increased permeability of glomerular capillary wall and their subsequent impaired reabsorption by the epithelial cells of the proximal tubuli [51], or the consequence of urea breakdown by bacteria in an alkaline environment (urine pH > 8). Grahofer et al. (2020) in their recent report of biomarkers for diagnosis of cystitis in sows, identified and proposed the presence of proteinuria as one of the most reliable and sensitive urinalysis biomarkers, in comparison to the gold standard of histopathology. In human medicine, Carter et al. (2006) [52] also reported an association between proteinuria and bacteriuria but the causative relationship remained undefined. In swine, proteinuria was associated with renal damage in an experimental study of Ravnskov et al. (1975) [53]. Carr et al. (1995) reported that in cases of failure of lower urinary tract defenses, such as in the case of cystitis, bacterial disease processes could result in damage of ureterovesicular junction, leading to pyelonephritis, due to vesicoureteric reflux. Ureteric valves in UTI affected sows are shortened from their normal length, and bacteria from the cyst can reflux back to the kidney [11]. In this study we did not investigate the impact of potential co-existence of glomerulonephritis and cystitis but, given the detected association between proteinuria and increased risk of cystitis, future studies should attempt to investigate its clinical importance.

Although in previous studies $[16,41]$ researchers reported no correlation between presence of cystitis and urine $\mathrm{pH}$, we found that higher $\mathrm{pH}$ values were associated with increased odds of bacteriuria or, with decreased odds for a sow to have lesions of acute and/or chronic cystitis, compared to having a normal bladder. It has been shown that alkaline $\mathrm{pH}$ supported the development of certain urinary sediment and was associated with bacteriuria. Nonetheless, a causative relationship between alkaline urinary $\mathrm{pH}$ and bacteriuria is difficult to establish because it is affected by several factors [23]. In some studies, the acid-base balance of the diet was correlated with urinary $\mathrm{pH}$ and total bacteria colony forming units in urine $[48,54]$. Lowering of urine $\mathrm{pH}$ was proposed as a mean to inhibit or control urinary bacterial overgrowth [42]. In sows with urinary tract infection, urine alkalization may result from urea transformation into ammonia by the bacterial flora [54]. Therefore, high urine $\mathrm{pH}$ may be the result of the presence and the metabolism of bacteria, or may precede or even trigger the colonization of the urinary tract with bacteria. In the cross-sectional context of this study inferences about the exact role and the potential causal effect of urine $\mathrm{pH}$ in UTI are not justified.

Presence of sediment was associated with higher odds of bacteriuria. Kauffold et al. (2010), using ultrasonography, reported that sows with UTI, defined on the basis of high bacterial count and macroscopic/biochemical urine abnormalities, were more likely to have high or moderate amounts of sediment in urine than those without UTI. Recently, Grahofer et al. (2020), also concluded that evaluation of presence of sediment is useful to detect sows with cystitis and bacteriuria.

\section{Conclusion}

In conclusion, in the present study we found that cystitis was quite frequent, affecting almost half of sows studied. The majority of sows with bacteriuria had histologically confirmed cystitis. We found that in most cases bacteria isolated from urine were mainly part of the normal intestinal flora which points to environmental and managerial involvement in the causality of UTI. Proteinuria was associated with both cystitis and bacteriuria, while urine turbidity was highly associated with bacteriuria; almost 2 out of 3 sows with bacteriuria had turbid urine. Therefore, urine turbidity and proteinuria appear as valuable diagnostic tools for clinical diagnosis of cystitis in sows.

\section{Abbreviations}

UTI: Urinary tract infection; Cl: Confidence interval; OR: Odds ratio; H\&E: Hematoxylin and eosin; HL: Hosmer-Lemeshow; PR: Pulkstenis-Robinson

Acknowledgements

Not applicable.

Authors' contributions

$M C$ visited the abattoirs and collected the data, performed the statistical analysis and drafted the manuscript. VS performed the statistical analysis and drafted the manuscript. VP and CM pathologically examined the urinary bladders collected. FK together with SC, PF and GP assisted with data 
collection from the abattoirs and drafting the manuscript. EP performed urinalysis and microbiological testing of urine samples. LL attracted funding, designed the study, selected the herds which participated in the study, guided the statistical analysis and critically revised the manuscript. All authors read and approved the final manuscript.

\section{Funding}

This research has been co-financed by the European Regional Development Fund of the European Union and Greek national funds through the Operational Program Competitiveness, Entrepreneurship and Innovation, under the call RESEARCH - CREATE - INNOVATE project T1EDK -02073- FITSOW.

\section{Availability of data and materials}

Available from senior author upon request.

\section{Declarations}

\section{Ethics approval and consent to participate}

This study was conducted in farms that complied with the current laws concerning the protection of animals kept for farming in the European Union [55]. Approval of the study protocol by an animal care committee was not required because taking part in the study was in no way painful or invasive for the animals.

\section{Consent for publication}

Not applicable.

\section{Competing interests}

The authors declare that they have no competing interests.

\section{Author details}

'Department of Epidemiology, Biostatistics and Economics of Animal Production, School of Veterinary Medicine, University of Thessaly, 43132 Karditsa, Greece. ${ }^{2}$ Laboratory of Animal Husbandry, Faculty of Veterinary Medicine, School of Health Sciences, Aristotle University of Thessaloniki, 54124 Thessaloniki, Greece. ${ }^{3}$ Laboratory of Microbiology and Infectious Diseases, Faculty of Veterinary Medicine, School of Health Sciences, Aristotle University of Thessaloniki, 54124 Thessaloniki, Greece. ${ }^{4}$ Laboratory of Pathology, Faculty of Veterinary Medicine, School of Health Sciences, Aristotle University of Thessaloniki, 54124 Thessaloniki, Greece.

\section{Received: 2 December 2020 Accepted: 7 April 2021}

\section{Published online: 19 April 2021}

\section{References}

1. Sanz M, Roberts JD, Perfumo CJ, et al. Assessment of sow mortality in a large herd. J Swine Health Prod. 2007;15(1):30-6.

2. Huirne RB, Dijkhuizen AA, Renkema JA. Economic optimization of sow replacement decisions on the personal computer by method of stochastic dynamic programming. Livest Prod Sci. 1991;28(4):331-47. https://doi.org/1 0.1016/0301-6226(91)90014-H.

3. Biksi I, Takacs N, Vetesi F, Fodor L, Szenci O, Fenyo E. Association between endometritis and urocystitis in culled sows. Acta Vet Hung. 2002;50(4):41323. https://doi.org/10.1556/avet.50.2002.4.4

4. Bilkei G, Bölcskei A, Goos T. Pathological changes in the urogenital tract and mammae of culled sows from an industrial pig production unit. Tierärztl Prax. 1995;23(1):37-41

5. Glock XT, Bilkei G. The effect of postparturient urogenital disease on the lifetime reproductive performance of sows. Can vet j. 2005 December; 46(12):1103-7.

6. Boma MH, Bilkei G. Gross pathological findings in sows of different parity, culled due to reoccurring swine urogenital disease (SUGD) in Kenya. Onderstepoort J Vet Res. 2006;73(2):139-42. https://doi.org/10.4102/ojvr.v73 i2.159.

7. Almond G. An assessment of urinary tract infections in sows. www.pork.org. 2005.

8. Vearick G, Melaggi AP, Bortolozzo FP, Wentz I, Bernardi ML. Causes of mortality in swine female. Arch Vet Sci. 2008;13(2):126-32.

9. Drolet R. Urinary system. In: Zimmerman JJ, Karriker LA, Ramirez A, Schwartz KJ, Stevenson GW, Zhang J. Diseases of swine. \#11th edition. John Wiley \& Sons; 2019. 417
10. Bara MR, McGowan MR, O'Boyle D, Cameron RD. A study of the microbial flora of the anterior vagina of norm sows during different stages of the reproductive cycle. Aust Vet J. 1990;70(7):256-9.

11. Muirhead MR, Alexander TJL. Cystitis and Pyelonephritis. In: Chapter 7 : Managing Health in the Gestation/Dry period. From: Managing Pig Health. A reference for the Farm. 5m Publishing. UK; 2013. p. 240-2.

12. Bellino C, Gianella P, Grattarola C, Miniscalco B, Tursi M, Dondo A, et al. Urinary tract infections in sows in Italy: accuracy of urinalysis and urine culture against histological findings. Vet Rec. 2013;172:183.

13. Alberton GC, Werner PR, Sobestiansky J, Costa OD, Barioni JW. Prevalence of urinary tract infections and of Actinomyces suis in urine from pregnant sows. Correlation with some urine's physical and chemical parameters. Arch Vet Sci. 2000;5:81-8.

14. Moura R, Caldara FR, Foppa L, Machado SP, Naas IA, Garcia RG, et al. Correlation between urinary tract infection and reproductive performance of sows. R Bras Zootec. 2018;21:47.

15. Madec F, Leon E. Farrowing disorders in the sow: A field study. J Vet Med. 1992;A 39:433-44.

16. Piassa MM, Merlini LS, Martins LA, Goncalves DD, Merlini NB, Caetano IC et al. Physical chemical and biological aspects of the urine of sows in a certified swine production farm in the city of Toledo, Parana, Brazil. Afr J Microbiol Res. 2015;9(7):414-9.

17. Grattarola C, Bergagna S, Zoppi S, Dondo A, Pinto L, Bossotto T, et al. Use of qualitative-quantitative bacteriological examination for diagnostic investigation of urinary tract infections in sows. XII congresso nazionale S.I. Di.L.V, Genova, Italia; 2010. p. 257-8.

18. Jones JT. An investigation of the causes of mortality and morbidity in sows in a commercial herd. Br Vet J. 1967;123(8):327-39. https://doi.org/10.1016/ S0007-1935(17)39852-4.

19. Jones JT. The cause of death in sows: a one-year survey of 106 herds in Essex. Br. Vet. J. 1968;124(2):45-55. https://doi.org/10.1016/S0007-1935(17)3 9551-9.

20. D' Allaire S, Drolet R, Chagnon M. The causes of sow mortality: A retrospective study. Can Vet J. 1991;32:241-3.

21. Chagnon M, D'Allaire S, Drolet R. A prospective study of sow mortality. Can J Vet Res. 1991:55(2):180-4.

22. Liebhold M, Wendt M, Kaup FJ, Drommer W. Clinical, and light and electron microscopical findings in sows with cystitis. Vet Rec. 1995;5:141-4.

23. Jackson PGG, Cockcroft PD. Cystitis and Pyelonephritis. Chapter 9: Diseases of the urogenital system and the mammary gland. In: Handbook of Pig Medicine. Philadelphia: Saunders-Elsevier; 2007.

24. King JM, Roth-Johnson L, Dodd DC, Newsom ME. THE NECROPSY BOOK: A guide for veterinary students, residents, clinicians, pathologists, and biological researchers. The Internet-First University Press; 2014. p. P66-7.

25. Cianciolo RE, Mohr FC. Chapter 4 - Urinary System. In: Grant Maxie M. Jubb, Kennedy \& Palmer's Pathology of Domestic Animals: Volume 2. Saunders Ltd; 2016. p. 459-61. https://doi.org/10.1016/C2012-0-00823-X.

26. Parrah JD, Moulvi BA, Gazi MA, Makhdoomi DM, Athar H, et al. Importance of urinalysis in veterinary practice - A review. Vet World. 6(9):640-6. https:// doi.org/10.14202/vetworld.2013.640-646.

27. Sink CA, Weinstein NM. Practical veterinary urinalysis. West Sussex UK: John Wiley \& Sons, Inc; 2012. p. 55-9.

28. Boerner SA, Lee YT, Kaufmann SH, Bible KC. The nitric acid method for protein estimation in biologic samples. In: Walker JM, editor. The protein protocols handbook. 2nd ed. New Jersey Totowa: Humana press; 2009. p. 31-41.

29. Volmer M, Wolthers BG, Metting HJ, de Haan TH, Coenegracht PM, van der Slik W. Artificial neural network predictions of urinary calculus compositions analyzed with infrared spectroscopy. Clin Chem. 1994;40(9):1692-7. https:// doi.org/10.1093/clinchem/40.9.1692.

30. Frochot V, Daudon M. Clinical value of crystalluria and quantitative morphoconstitutional analysis of urinary calculi. Int J Surg. 2016:36:624-32 https://doi.org/10.1016/j.ijsu.2016.11.023.

31. Lorrier JC, Valkenburg HA. Quantitative Urine Culture by Surface Drop Method. Appl Microbiol. 1969;18(1):57-63.

32. Lo Fo Wong DMA, Dahl J, Stege $H$, van der Wolf PJ, Leontides L, von Altrock $A$, et al. Herd-level risk factors for subclinical Salmonella infection in European finishing-pig herds. Prev Vet Med. 2004 Apr 16;62(4):253-66. https://doi.org/10.1016/j.prevetmed.2004.01.001.

33. Mickey J, Greenland S. A study of the impact of confounder-selection criteria on effect estimation. Am J Epidemiolog. 1989;129(1):125-37. https:// doi.org/10.1093/oxfordjournals.aje.a115101. 
34. Maarten LB. "OPARALLEL: Stata module providing post-estimation command for testing the parallel regression assumption," statistical software components S457720, Boston College Department of economics; 2019.

35. Fagerland MW, Hosmer DW. How to test for goodness of fit in ordinal logistic regression models. Stata J. 2017;17(Number 3):668-86.

36. Grahofer A, Bjorkman S, Peltoniemi O. Diagnosis of endometritis and cystitis in sows: use of biomarkers. J An Sci. 2020;98(Supplement_1):S107-16.

37. Gmeiner K. Ultrasonographis che Charakterisierung der gesunden und kranken Harnblasebei der Sau [doctoral dissertation]. Leipzig (Germany): University of Leipzig; 2007.

38. Mazutti K, Locatelli-Dittrich R, Lunardon I, Kuchiishi SS, de Lara AC, et al. Evaluation of the reagent test strips and microscopic examination of urine in the diagnosis of urinary tract infection in sows. Pesq Vet Bras. 2013;33:9.

39. Woldemeskel M, Drommer W, Wendt M. Microscopic and ultrastructural lesions of the ureter and renal pelvis in sows with regard to Actinobaculum suis infection. J Vet Med. 2002;49:348-52.

40. Carr J, Walton JR. Bacterial flora of the urinary tract of pigs associated with cystitis and pyelonephritis. Vet Rec. 1993;132(23):575-7. https://doi.org/1 $0.1136 /$ vr.132.23.575

41. Carr J, Walton J, Done S. Cystitis and ascending pyelonephritis in the sow. In Pract. 1995;17(2):71-9. https://doi.org/10.1136/inpract.17.2.71.

42. Moreno LZ, Matajira CE, Poor AP, Mesquita RE, Gomes VT, et al. Identification through MALDI-TOF mass spectrometry and antimicrobial susceptibility profiling of bacterial pathogens isolated from sow urinary tract infection. Vet Q. 2018;38(1):1-8.

43. Kauffold J, Gmeiner K, Sobiraj A, Richter A, Failing K, Wendt M. Ultrasonographic characterization of the urinary bladder in sows with and without urinary tract infection. Vet J. 2010;183(1):103-8. https://doi.org/10.1 016/j.tvjl.2008.09.008

44. Lorenzett MP, Cruz RA, Cecco BS, Schwertz Cl, Hammerschmitt ME, et al. Obstructive urolithiasis in growing-finishing pigs. Pesq Vet Bras. 2019;39(6): 382-7. https://doi.org/10.1590/1678-5150-pvb-6229.

45. Maes DG, Vrielinck J, Millet S, Janssens GP, Deprez P. Urolithiasis in finishing pigs. Vet J. 2004;168(3):317-22. https://doi.org/10.1016/j.tvjl.2003.09.006.

46. Dial GD, MacLachlan NJ. Urogenital infections of swine: I clinical manifestations and pathogenesis. Comp Contin Educ Pract Vet. 1988;10:6370.

47. Dee SA. Porcine Urogenital disease. In: Veterinary clinics of North America. Food animal practice, swine reproduction, vol. 8; 1992. p. 641-60.

48. Gusmara C, Andreoni S, Barzetti C, Sala V. Osservazioni diagnostiche sulle infezioni urinarie (UTI) della scrofa. Large Animal Rev. 2011;17:247-51.

49. Biksi I. Some aspects of urogenital tract diseases of female breeding swine Biksi dissertation; 2002.

50. D'Amico G, Bazzi C. Pathophysiology of proteinuria. Kidney Int. 2003;63(3): 809-25. https://doi.org/10.1046/j.1523-1755.2003.00840.x.

51. Carter JL, Tomson CR, Stevens PE, Lamb EJ. Does urinary tract infection cause proteinuria or microalbuminuria? A systematic review. Nephrol Dial Transplant. 2006;21(11):3031-7. https://doi.org/10.1093/ndt/gfl373.

52. Ravnskov U, Johansson BG, Ljunger L. Proteinuria in Pigs with Experimentally Induced Renal Damage. Contr Nephrol. 1975;1:50-61.

53. DeRouchey JM, Hancock JD, Hines RH, Cummings KR, Lee DJ, et al. Effects of dietary electrolyte balance on the chemistry of blood and urine in lactating sows and sow litter performance. J Anim Sci. 2003;81(12):3067-74. https://doi.org/10.2527/2003.81123067x.

54. Coles EH. Prueblas de funcionamento renal. In: Coles, EH Diagnóstico y patologia veterinária México: Interamericana 1989; 4:175-206.

55. European Council, et al. Official J Eur Commun. 8.8.98. Available at: http:// eurlex.europa.eu/LexUriServ/LexUriServ.do?uri=OJ:L:1998:221:0023:0027:EN: PDF. Accessed 1 Jan 2019.

\section{Publisher's Note}

Springer Nature remains neutral with regard to jurisdictional claims in published maps and institutional affiliations.

Ready to submit your research? Choose BMC and benefit from:

- fast, convenient online submission

- thorough peer review by experienced researchers in your field

- rapid publication on acceptance

- support for research data, including large and complex data types

- gold Open Access which fosters wider collaboration and increased citations

- maximum visibility for your research: over $100 \mathrm{M}$ website views per year

At BMC, research is always in progress.

Learn more biomedcentral.com/submissions 